\title{
Obesity Evaluation and Intervention During Family Medicine Well Visits
}

\author{
Debra Boardley, PhD, RD, Christopher Sherman, MD, Lisa Ambrosetti, MS, and \\ Jeffrey Lewis, $M D$
}

Purpose: The purpose of this study was to determine the extent that primary care providers assess overweight and obesity and offer treatment strategies during well visits in a family medicine setting.

Methods: This was a cross-sectional study of 553 consecutive patients who presented for family medicine well visits. Patient charts were reviewed for documentation of body mass index (BMI) and patient education regarding weight, exercise, and diet.

Results: BMI was calculated for $63.5 \%$ of adults at the well visit. For patients who were overweight or obese (BMI greater than 25 ), $48.9 \%$ received education on weight, $50.2 \%$ on diet, and $41 \%$ on exercise. Adults who had BMI calculated were also more likely to receive weight-related education $(P<.001)$. Although height and weight were measured for most of the children and adolescents, their BMI-for-age was not calculated and they were unlikely to receive weight-related education.

Conclusions: Training staff to measure and record BMI is a useful prompt for the physician to discuss overweight. To address weight during critical periods of development, children and adolescents need to have growth monitored with standardized tools. (J Am Board Fam Med 2007;20:252-257.)

Obesity is a growing epidemic in the United States that increases mortality and aggravates common medical conditions. Approximately 32\% of adults in the United States, more than 60 million, are classified as obese as defined by BMI greater than $30 .{ }^{1}$ In adults, excess weight increases the risk of many chronic diseases, including heart disease, hypertension, diabetes, cancer, stroke, and osteoarthritis. ${ }^{2}$ Overweight in children and adolescents is defined as at or above the 95 th percentile using sexand age-specific growth charts. ${ }^{3}$ In 2003 to 2004, $17.1 \%$ of children and adolescents were overweight. ${ }^{1}$

The current obesity epidemic has significant future implications to our health care system. It is estimated that health care expenditures related to obesity and overweight in adults are approximately

This article was externally peer reviewed.

Submitted 31 July 2006; revised 28 November 2006; accepted 8 December 2006.

From the Department of Public Health, University of Toledo, Toledo, OH (DB); Flower Hospital Family Medicine Residency Program, Sylvania, OH (CS); the University of Toledo, Toledo, OH (LA); and the Toledo Hospital Family Practice Residency, Toledo, OH (JL).

Funding: none.

Conflict of interest: none declared.

Corresponding author: Debra Boardley, PhD, Department of Public Health, Mail Stop 119, 2801 West Bancroft, University of Toledo, Toledo, OH 43623 (E-mail: debra.boardley@utoledo.edu).
$\$ 117$ billion each year. ${ }^{4,5}$ Given the number of patients affected, the comorbid health implications, and the economic impact, primary care providers have been urged to place significant emphasis on the diagnosis and treatment of obesity during preventive health physical examinations. ${ }^{6,7}$ It is estimated that every month, primary care physicians see $11.3 \%$ of the US population. ${ }^{8}$ This provides an opportunity for intervention. Orzano and $\mathrm{Scott}^{9}$ reviewed recommendations from many scientific bodies addressing obesity in adults. They concluded that clinicians should manage obesity as a chronic relapsing condition and recommended patient education strategies to manage overweight and obese adult patients. The Institute of Medicine report, Preventing Childhood Obesity: Health in the Balance ${ }^{10}$, recommends health professionals to routinely track BMI and to offer patients evidencebased guidance on weight control.

Measuring BMI is an effective measure for overweight and obesity; it is considered to be reliable, inexpensive, and quick. ${ }^{11}$ Even with the recommendations to identify and treat overweight and obesity, the prevalence of undiagnosed obesity in currently obese US adults is $22.9 \% .{ }^{12}$ The high rate of undiagnosed obesity may be explained by the fact that, despite the availability and ease of measuring BMI, research has shown that it is frequently not used. ${ }^{13}$ Even when a formal diagnosis 
of obesity is made, clinicians may not provide patients with advice regarding weight loss. One study of obese patients seeking medical help for comorbid conditions found that only $27 \%$ to $42 \%$ were advised by their primary care physician to lose weight. ${ }^{13}$ In a national study of 12,835 adults classified as obese, only $42 \%$ reported that their health care provider advised them to lose weight. ${ }^{14}$

The purpose of this study was to determine the extent that primary care providers assess overweight and obesity and document treatment strategies in a family medicine setting during well visits. Review of medical records provided data to assess the use of BMI for adults and BMI-for-age for children and allowed examination of the documentation of patient education concerning body weight, diet, and exercise.

\section{Methods \\ Subjects}

Two large family medicine practices participated in this cross-sectional observational study. The practices were located in a Midwestern city. The larger practice, with 25 family medicine physicians, was located in an urban setting, and the other, with 22 physicians, was in a suburban setting. Both practice sites provide training for family medicine residents. Charts for all consecutive patients 2 years of age and older, who visited the office for 3 months in 2005 (February, March, and April), and who were seeing the physician for a well visit were reviewed. The research protocol was reviewed and approved by the Institutional Review Board.

\section{Measures}

To ensure consistency, the same 2 researchers worked together to review all charts. The variables collected included: practice location, physician name, patient age, patient sex, and BMI at last visit. If BMI was not recorded for the well visit, BMI for any visit was noted. In cases where there was not a BMI recorded at well visit, but height and weight were recorded, the researchers recorded these measures and BMI was calculated using the formula for BMI: weight in kilograms divided by height in meters squared. The children's charts were reviewed for the previously identified variables. In addition, the use of BMI-for-age or any other growth charts was noted.
To determine the level of instruction the patient received regarding weight, diet, and exercise, the chart note for the well visit was reviewed and coded using a 3-point scale; "none," "minimal," and "detailed." A score of "none" was recorded when the physician note did not indicate any discussion of, or plan to address weight, diet, or exercise. If the chart note included some mention of weight, diet, or exercise, "minimal" was recorded. For example, "minimal" was used if the chart note included general comments such as "patient was encouraged to lose weight," "discussed diet," and "encouraged exercise." To receive "detailed," there was documentation of specific goals or educational plan. Examples of "detailed" included referrals for further education, scheduled follow-up to assess progress ("come back in 6 months for weight and cholesterol check"), noting the educational materials used ("gave patient handouts and discussed portion sizes"), and specific goals ("walk 3 times a week").

\section{Data Analysis}

Descriptive statistics were used to describe the sample, the measurement of BMI and the amount and level of patient education. The $\chi^{2}$ statistic was used to test the association of level of education with patient weight category (overweight BMI, 25 or greater; obese, 30 or greater, and morbid obese, 40 or greater). In adults, the levels of education were then collapsed to a binary variable (no documented education, any documented education), and another $\chi^{2}$ analysis compared education with the number of adults who had BMI measured in their well visit. In children, the analysis of education to weight category included normal, at risk of overweight, and overweight. The $\chi^{2}$ statistic was also used to assess the association between a child's age and use of growth charts. Associations were considered significant if $P<.05$.

\section{Results}

Data were collected from 553 charts, 405 adults, and 148 children. Patient characteristics are summarized in Table 1. In the adults, 257 (63.5\%) had BMI noted in chart for their well visit. For 115 adults, height and weight were recorded and BMI was then calculated by the researchers. Another 26 adult charts had BMI recorded within the last year. In this sample, only $21 \%$ of the adult patients had a BMI less than 25. BMI-for-age was not used in 
Table 1. Demographic Characteristics and BMI of Patients Presenting for Preventive Care to Family Medicine Providers

\begin{tabular}{lc}
\hline Characteristic & $\begin{array}{c}\text { Percentage or } \\
\text { Mean } \pm \text { SD }\end{array}$ \\
\hline Adults (n = 405) & \\
Female & $227(56 \%)$ \\
Male & $178(44 \%)$ \\
Age & $48.1 \pm 15.5$ years \\
BMI calculated at well visit & $257(63 \%)$ \\
Height/weight measured at well visit & $112(28 \%)$ \\
BMI calculated within past year & $26(6 \%)$ \\
No height or weight in chart & $10(2.5 \%)$ \\
BMI category & \\
Underweight (less than 18.5) & $8(2 \%)$ \\
Normal (18.5 to 24.9) & $80(20 \%)$ \\
Overweight (25 to 29.9) & $128(32 \%)$ \\
Obese (30 to 39.9) & $150(38 \%)$ \\
Morbidly obese (greater than 40$)$ & $29(7 \%)$ \\
Children (n = 148) & \\
Female & $85(57 \%)$ \\
Male & $63(43 \%)$ \\
Age & \\
BMI-for-age calculated & \\
Height and weight measured & \\
CDC BMI-for-age category* & \\
Underweight (below 5th & \\
bercentile) & \\
Otile) & \\
\hline
\end{tabular}

*BMI-for-age calculated from charted height, weight, and age data and compared with percentile standards are available at www.cdc.gov/nccdphp/dnpa/bmi/childrens_BMI/ about_childrens_BMI.htm.

any child chart in this sample. Height and weight were recorded for $95 \%$ of the children, and these data were used to calculate the BMI-for-age information that is presented. In this sample, $47 \%$ of the children were overweight or at risk of overweight.

Although most of the adults and almost half of the children had BMI's above normal, many of the charts did not document any education or discussion concerning weight, diet or exercise. Table 2 presents adult information. For patients with BMI measurements of 25 or greater, $48.9 \%$ received some level of education concerning weight, $50.8 \%$ were counseled on diet, and $41 \%$ received advice about exercise. There was a significant increase in patient education with increasing body weight. Obese and morbidly obese patients received more education on weight $(P=.029)$ and $\operatorname{diet}(P=.025)$ than did overweight patients. For those patients with BMI measurements of 30 or greater, the physicians provided education concerning weight to $56.4 \%$, diet to $55.3 \%$, and exercise to $45 \%$. Exercise education had the lowest amount of documentation, and this did not change with weight category.

Interestingly, the recording BMI affected the amount of documented education. For adults with above-normal weight, 202 had BMI measurements documented at the well visit, whereas 105 did not. A $\chi^{2}$ analysis showed that patients who had their BMI measured and recorded in the chart were more likely to have documented education, compared with those who did not have BMI measured $(P<.001)$.

Very few at-risk-for-overweight and overweight children in this sample had documented evidence of education about weight, diet, and exercise (Table 3). Although BMI-for-age is the recommended standard for evaluating weight in children, none of the charts indicated that this tool was being used. Standard growth charts were in many of the charts, and physicians often noted weight percentiles, but the use of growth charts decreased with the increased age of the child (Table 4).

\section{Discussion}

In this retrospective study, patient charts were reviewed to determine whether the family medicine providers were using preventive (well) visits to address overweight and obesity. The most important and practical finding was the evidence that, when $\mathrm{BMI}$ is measured and documented, the physician is more likely to document patient education regarding weight, diet, and exercise. Training staff to measure height and weight and calculate BMI makes this information available and may cue the physician to provide and document weight-related education.

To help reverse the current trend of obesity in the United States, primary care providers must not only recognize and document obesity, but also treat it as a chronic disease by providing patient education concerning weight, diet, and exercise. In the current study, $56.4 \%$ of the obese patients received documented information on weight, $55.3 \%$ were given diet advice, and only $45 \%$ were instructed to exercise. 
Table 2. Percentage of Adult Patients with Chart Documentation of Weight-Related Education by BMI Category

\begin{tabular}{|c|c|c|c|c|}
\hline \multirow[b]{2}{*}{ Education Type } & \multicolumn{4}{|c|}{ BMI Category } \\
\hline & $\begin{array}{c}\text { Overweight (25 to } 29.9) \\
\mathrm{n}=128\end{array}$ & $\begin{array}{l}\text { Obese (30 to } 39.9) \\
n=150\end{array}$ & $\begin{array}{c}\text { Morbidly Obese (Greater than } 40 \text { ), } \\
n=29\end{array}$ & $\begin{array}{l}\text { Total, } \\
\mathrm{n}=307\end{array}$ \\
\hline \multicolumn{5}{|c|}{ Weight education* } \\
\hline None & $79(62 \%)$ & $67(45 \%)$ & $11(38 \%)$ & $157(51 \%)$ \\
\hline Minimal & $39(30 \%)$ & $65(43 \%)$ & $13(45 \%)$ & $117(38 \%)$ \\
\hline Detailed & $10(8 \%)$ & $18(12 \%)$ & $5(17 \%)$ & $33(11 \%)$ \\
\hline \multicolumn{5}{|l|}{ Diet education $\dagger$} \\
\hline None & $71(56 \%)$ & $68(41 \%)$ & $12(41 . \%)$ & $151(49 \%)$ \\
\hline Minimal & $44(34 . \%)$ & $67(44 \%)$ & $9(31 \%)$ & $120(39 \%)$ \\
\hline Detailed & $13(10 \%)$ & $15(10 \%)$ & $8(28 \%)$ & $36(12 \%)$ \\
\hline \multicolumn{5}{|c|}{ Exercise education $\neq$} \\
\hline None & $83(65 \%)$ & $82(55 \%)$ & $16(55 \%)$ & $181(59 \%)$ \\
\hline Minimal & $35(28 \%)$ & $57(38 \%)$ & $9(31 \%)$ & $102(33 \%)$ \\
\hline Detailed & $9(7 \%)$ & $11(7 \%)$ & $4(14 \%)$ & $24(8 \%)$ \\
\hline
\end{tabular}

${ }^{*} \chi^{2}=10.78, \mathrm{df}=4, P=.029$

$\dagger \chi^{2}=11.11, \mathrm{df}=4, P=.025$

$\ddagger \chi^{2}=4.8, \mathrm{df}=4, P=.305$.

These findings are similar to those of a national study of weight management practices, ${ }^{15}$ which found that for obese patients, $35.5 \%$ received weight loss advice, $32.8 \%$ received exercise advice, and $41.5 \%$ received diet advice from their physician. Another more recent investigation $^{16}$ observed the amount of advice that primary care providers gave obese patients and re- ported that $65.1 \%$ of patients received information about the benefits of weight loss, whereas only $36.6 \%$ were given specific weightcontrol advice and $28.2 \%$ were instructed to increase physical activity. Similar to previous research, ${ }^{15,16}$ this study found that physicians are more likely to offer education on diet than on exercise.

Table 3. Percentage of Children and Adolescents with Documented Weight-Related Education by BMI Category

\begin{tabular}{|c|c|c|c|c|}
\hline \multirow[b]{2}{*}{ Education Type } & \multicolumn{4}{|c|}{ BMI Category } \\
\hline & $\begin{array}{c}\text { Healthy Weight } \\
\text { (5th to Below 85th } \\
\text { Percentile), } \\
\text { n }=73\end{array}$ & $\begin{array}{l}\text { At Risk of Overweight } \\
\text { (85th to Below 95th } \\
\text { Percentile), } \\
\mathrm{n}=38\end{array}$ & $\begin{array}{c}\text { Overweight } \\
\text { (Above 95th Percentile), } \\
\mathrm{n}=28\end{array}$ & $\begin{array}{c}\text { Total, } \\
\mathrm{n}=139\end{array}$ \\
\hline \multicolumn{5}{|c|}{ Weight education* } \\
\hline None & $44(60 \%)$ & $19(50 \%)$ & $13(46 \%)$ & $76(55 \%)$ \\
\hline Minimal & $29(40 \%)$ & $19(50 \%)$ & $14(50 \%)$ & $62(45 \%)$ \\
\hline Detailed & 0 & 0 & $1(4 \%)$ & $1(<1 \%)$ \\
\hline \multicolumn{5}{|l|}{ Diet education $\dagger$} \\
\hline None & $34(47 \%)$ & $16(42 \%)$ & $11(39 \%)$ & $61(44 \%)$ \\
\hline Minimal & $39(53 \%)$ & $22(58 \%)$ & $15(54 \%)$ & $76(55 \%)$ \\
\hline Detailed & 0 & 0 & $2(7 \%)$ & $2(1 \%)$ \\
\hline \multicolumn{5}{|c|}{ Exercise education $\neq$} \\
\hline None & $42(58 \%)$ & $18(47 \%)$ & $14(50 \%)$ & $74(53 \%)$ \\
\hline Minimal & $31(42 \%)$ & $20(53 \%)$ & $13(46 \%)$ & $64(46 \%)$ \\
\hline Detailed & 0 & 0 & $1(4 \%)$ & $1(<1 \%)$ \\
\hline
\end{tabular}

${ }^{*} \chi^{2}=5.703, \mathrm{df}=4, P=.22$

$\dagger \chi^{2}=8.31, \mathrm{df}=4, P=.081$

$\ddagger \chi^{2}=5.080, \mathrm{df}=4, P=.279$. 
Table 4. Percentage of Child and Adolescent Medical Charts with Standardized Growth Charts

\begin{tabular}{lll}
\hline Age Group & $\mathrm{n}$ & Number with Growth Charts \\
\hline 2 to 5 years & 41 & $41(100 \%)$ \\
6 to 10 years & 29 & $27(93 \%)$ \\
11 to 14 years & 33 & $20(61 \%)$ \\
15 to 18 years & 45 & $15(33 \%)$ \\
\hline
\end{tabular}

$\chi^{2}=55.87, \mathrm{df}=3, P<.001$.

It seems that primary care providers are missing opportunities during preventive visits to help their patients. In fact, patients report that they want more help with weight management from their primary care physician. ${ }^{17}$ Recently, Bish et $\mathrm{al}^{18}$ reported that adults who had a routine physician checkup in the previous year and also reported that they had received medical advice to lose weight were much more likely to try to lose weight, compared with adults who had a checkup but did not receive medical advice to lose weight.

Another important finding of this study was that children did not have BMI-for-age measured, and were not likely to receive education about weight, diet, or exercise. Although BMI-for-age was never noted, growth charts were often used and provided a method to monitor growth for children up to 10 years of age. Unfortunately, after age 10, there was a significant decline in the use of growth charts. It is known that puberty is a critical time for the development of overweight, ${ }^{19}$ and unfortunately, these adolescents were not being monitored with BMI-for-age or growth charts.

The evaluation of education was based on the physician chart note and is a limitation that may underestimate the true amount of education that was provided. It is very possible that education was given but not documented. However, these were all routine well visits. It would be difficult to implement and follow up on a plan to address weight, diet, or exercise without documenting the education that was provided.

\section{Conclusions}

Family medicine physicians can use well visits to offer strategies to treat overweight and obesity in children and adults. Training staff to measure and document $\mathrm{BMI}$ is a useful prompt for the physician to discuss overweight. Children need to have BMIfor-age calculated at each well visit to follow weight throughout childhood and adolescence. Future research is needed to determine whether weightrelated education during well visits is effective in helping patients achieve and maintain healthy weight.

\section{References}

1. Ogden CL, Carroll MD, Curtin LR, et al. Prevalence of overweight and obesity in the United States, 1999-2004. JAMA 2006;295:1549-55.

2. Stein CJ, Colditz GA. The epidemic of obesity. J Clin Endocrinol Metab 2004;89:2522-5.

3. Kuczmarski RJ, Ogden CL, Grummer-Strawn LM. CDC Growth Charts: United States. Adv Data 2000; 314:1-27.

4. Daviglus ML, Liu K, Yan LL, et al. Relation of body mass index in young adulthood and middle age to Medicare expenditures in older age. JAMA 2004;292: 2743-9.

5. U.S. Department of Health and Human Services. The Surgeon General's call to action to prevent and decrease overweight and obesity. Rockville MD: US Department of Health and Human Services, Public Health Service, Office of the Surgeon General; 2001.

6. Nawaz H, Katz DL. American College of Preventive Medicine Practice Policy statement. Weight management counseling of overweight adults. Am J Prev Med 2001;21:73-8.

7. American Academy of Pediatrics Committee on $\mathrm{Nu}$ trition. Prevention of Pediatric Overweight and Obesity. Pediatrics 2003;112:424-30.

8. Noel M, Hickner J, Ettenhofer T, Gauthier B. The high prevalence of obesity on Michigan primary care practices. An UPRNet study. Upper Peninsula Research Network. J Fam Prac 1998;47:39-43.

9. Orzano AJ, Scott JG. Diagnosis and treatment of obesity in adults: an applied evidence-based review. J Am Board Fam Pract 2004;17:359-69.

10. Koplan J, Liverman C, Kraak VI. Preventing childhood obesity: health in the balance: executive summary. J Am Diet Assoc 2005;105:131-8.

11. Clinical guidelines on the identification, evaluation, and treatment of overweight and obesity in adults: executive summary. Expert panel on the identification, evaluation, and treatment of overweight in adults. Am J Clin Nutr 1998;68:899-917.

12. Diaz VA, Mainous AG III, Koopman RJ, Geesey ME. Undiagnosed obesity: implications for undiagnosed hypertension, diabetes, and hypercholesterolemia. Fam Med 2004;36:639-44.

13. Galuska DA, Will JC, Serdula MK, Ford ES. Are health care professionals advising obese patients to lose weight? JAMA 1999;282:1576-8.

14. Lemay CA, Cashman S, Savageau J, et al. Underdiagnosis of obesity at a community health center. J Am Board Fam Pract 2003;16:14-21. 
15. Stafford RS, Farhat JH, Misra B, Schoemfeld DA. National patterns of physician activities related to obesity management. Arch Fam Med 2000; 9:631-8.

16. Simkin-Silveramn LR, Gleason KA, King WC, et al. Predictors of weight control advice in primary care practices: patient health and psychosocial characteristics. Prev Med 2005;40:71-82.

17. Potter MB, Vu JD, Croughan-Minihane M. Weight management: what patients want from their primary care physicians. J Fam Pract 2001;50:513-18.

18. Bish C, Blanck HM, Serdula M, et al. Diet and physical activity behaviors among Americans trying to lose weight: 2000 Behavioral Risk Factor Surveillance System. Obes Res 2005;13:596-607.

19. Whitaker RC, Wright JA, Pepe MS, Seidel KD, Dietz WH. Predicting obesity in young adulthood from childhood and parental obesity $\mathrm{N}$ Engl J Med 1997;337:869-73. 